\title{
Utilization of the public space in gelanggang olahraga Area H. Agus Salim Padang
}

\author{
Afriani Nanda Sari ${ }^{1}$, Afriva Khaidir ${ }^{2}$ \\ ${ }^{1}$ Social Education Program, Universitas Negeri Padang \\ ${ }^{2}$ Universitas Negeri Padang
}

\begin{abstract}
Public space is the most important component in urban spatial planning. Public space can be interpreted as a place or space that can be accessed or utilized by all communities or communities can gather for the same purpose. With the existence of public space the community can establish direct social interaction. So public spaces in urban areas can provide physical and psychological benefits to users. The research approach used is a qualitative approach with a descriptive research type. The selection of informants in this study used purposive sampling. The data collection techniques and tools used in three ways are nonparticipant observation, interviews and documentation. To achieve the validity of the research data using triangulation techniques. Meanwhile the data analysis technique uses technical analysis of Miles and Huberman data, namely data reduction, data presentation and conclusion drawing. The results of this study can be concluded (1) Strategic location, (2) Easy access, (3) areas that have attraction, (4) Weak social control.
\end{abstract}

Keywords: utilization of public space

This is an open access article distributed under the Creative Commons Attribution License, which permits unrestricted use,

distribution, and reproduction in any medium, provided the original work is properly cited. (C2018 by author

\section{PENDAHULUAN}

Perkembangan di kawasan pusat kota ditandai dengan adanya tuntutan dan kebutuhan masyarakat kota yang semakin beranekaragam, terutama dalam hal kenyamanan, pelayanan dan fasilitas infrastruktur. Fasilitas Infrastruktur kota merupakan aspek yang mendasar dalam pembentukan sebuah kota, berfungsi untuk mendukung kegiatan-kegiatan publik agar dapat berjalan dengan optimal. Hal ini ditandai oleh berbagai fasilitas seperti taman kota, trotoar, jalan, penerangan umum, halte, tempat pembuangan sampah, pasar, tempat rekreasi, tempat ibadah, tempat olahraga dan lain sebagainya yang disediakan oleh pemerintah. Ruang publik merupakan salah satu kebutuhan pokok bagi masyarakat kota sehingga bisa terjalin interaksi sosial di masyarakat kota itu sendiri. Selain itu interaksi sosial warga masyarakat sangat penting dalam menjaga dan meningkatkan solidaritas antar masyarakat perkotaan. Menurut Hakim dalam (Budihardjo, 1999: 89), ruang publik merupakan suatu wadah yang dapat emanmpung aktivitas/kegaiatan tertentu dari masyarakatnya, baik secara individual maupun kelompok. Ruang publik sebaiknya ditata atau didesain dan dikelola untuk memenuhi kebutuhan para pengguna.

Pemanfaatan ruang publik sebagai ruang untuk dapat beraktivitas sosial maupun ekonomi selain itu ruang publik ini dapat memberikan atau menyediakan akses untuk beraktivitas, sumber daya, informasi dan tempat agar masyarakat dapat memanfaatkannya secara bersama atau umum. Dengan demikian ruang publik kota tidak memihak pada kepentingan tertentu, bersifat terbuka, demokratis, dan dapat dijangkau oleh siapa saja. Menurut Carr (Anita dkk, 2012: 3) terdapat tiga kualitas utama sebuah ruang publik, yaitu tanggap (responsive) berarati bahwa ruang tersebut dirancang dan dikelola dengan mempertimbangkan kepentingan para penggunanya, tidak mementingkan kepentingan pribadi. Demokratis (democratic) berarti bahwa hak para pengguna ruang publik 
tersebut terlindungi, pengguna ruang publik bebas berekspresi dalam ruang tersebut, namun tetap memiliki batasan tertentu karena dalam penggunaan ruang bersama perlu ada toleransi diantara para pengguna ruang agar tidak terjadinya hal-hal yang tidak diinginkan seperti konflik. Bermakna (meaningful) berarti mencakup adanya ikatan emosional antara ruang tersebut dengan kehidupam para penggunananya. Masyarakat sebagai pengguna ruang publik tersebut memaknai sebuah tempat umum dijadikan sebagai untuk beraktivitas dalam ruang yang sama.

Kota Padang merupakan salah satu kota penyedia ruang publik untuk masyarakatnya. Kebutuhan masyarakat kota pada fasilitas umum yang harus dipenuhi oleh pemerintah. Salah satu upaya penyediaan ruang publik di Kota Padang adalah gelanggang olahraga yang dikenal dengan GOR H. Agus Salim merupakan salah satu fasilitas publik dengan dilengkapi sarana dan prasarana olahraga. Kawasan GOR H. Agus Salim ini memiliki total luas $94.824 \mathrm{M} 2$ dengan sarana olahraga memiliki luas $52.847 \mathrm{M} 2$, tempat pameran memiliki luas 5.464 M2, kantor DISPORA memiliki luas 350 M2, jalan memiliki luas 25.785 M2 dan tempat parkir dengan memiliki luas 10.376 M2. Kawasan GOR H. Agus Salim cukup luas ini dapat di akses oleh semua kalangan masyarakat untuk beraktifitas. Kawasan GOR H. Agus Salim tidak hanya sebagai tempat melakukan aktivitas olahraga tetapi juga dimanfaatkan sebagai tempat untuk mengadakan berbagai kegiatan. Adapun kegiatan yang telah diadakan dikawasan GOR ini seperti Dragon Boat, pacu dayung, pameran pelaku usaha kecil dan produk kerajinan rakyat, padang fair, festival-festival, bazar dan lain sebagainya. Selain itu kawasan GOR H. Agus Salim juga dimanfaatkan sebagai tempat latihan mengemudi. Dengan demikian GOR H. Agus Salim memiliki potensi untuk menarik masyarakat untuk berkunjung sekaligus menggunakan kawasan ini untuk kepentingan pribadi seperti bermunculanya laki-laki meyerupai wanita (waria), transaksi wanita pekerja malam pada malam harinya dan maupun digunakan untuk kepentingan pribadi lainnya.

Hal ini berdampak kepada bermunculannya aktivitas-aktivitas informal atau pedagang kaki lima (PKL) yang menempati dan memanfaatkan lokasi-lokasi publik sebagai tempat berjualan. Menurut Sidharata (Handayani Suci, 2009: 35) PKL sebagai pedagang informal yang menempati kaki lima (trotoar-pedestrian) yang keberadaannya tidak boleh mengganggu fungsi publik, baik ditinjau dari aspek ekonomi, sosial, fisik visual, lingkungan, dan pariwisata. Sedangkan tempat usaha pedagang kaki lima didefinisikan sebagai tempat umum, yaitu tepi-tepi jalan umum, trotoar, lapangan, serta tempat lainnya, di atas tanah Negara, yang ditetapkan oleh Walikota Kepala Daerah. Sementara pada Peraturan Daerah (Perda) Kota Padang No 3 Tahun 2014 tentang Pemerataan dan Pembedayaan Pedagang Kaki Lima. Adanya pihak-pihak yang memanfaatkan kawasan GOR H. Agus Salim juga dimanfaatkan oleh para premenisme dan pengemis. Selain itu para pengemis juga memanfaatkan kesempatan tersebut untuk meminta-minta/mengemis kepada masyarakat yang berkunjung ke kawasan GOR H. Agus Salim. Dengan demikian kawasan GOR H. Agus Salim selain untuk dimanfaatkan oleh pihak-pihak tertentu juga bepotensi menimbulkan permasalahan seperti parkir liar, perilaku buang sampah sembarangan, tidak tertib aturan dan konflik. Maka penelitian ini akan menjelaskan tentang faktor-faktor yang mempengaruhi terjadinya pemanfaatan ruang publik. Fenomena pemanfataan ruang publik yang tidak sesuai dengan peruntukannya tersebut menimbulkan berbagai pertanyaan di dalam kepala peneliti sehingga peneliti merasa perlu untuk melakukan penelitian dengan judul pemanfaatan ruang publik di kawasan GOR H. Agus Salim Kota Padang.

\section{METODE}

Berdasarkan latar belakang di atas maka dalam penelitian ini menggunakan pendekatan kualitatif. Dengan tipe penelitian deskiriptif karena tipe penelitan ini dapat menggambarkan dan mejelaskan sebuah fenomena. Adapun pemilihan informan disini dengan purposive sampling yaitu menentukan kriteria informan penelitian, dengan teknik pengumpulan data menggunakan teknik observasi, wawancara terstruktur dan dokumentasi. Teknik pemeriksaan data menggunakan triangulasi data. Adapun analisis data menggunakan analisis data Miles dan Huberman (1983:33).

\section{HASIL}

Terjadinya pemanfaatan ruang publik di kawasan GOR H. Agus Salim yang tidak sesuai fungsinya adalah suatu yang umum dilakukan oleh masyarakat. Beralih fungsinya ruang publik seiring dengan perkembangan aktivitas masyarakat. Tentunya ini akan menganggu fungsi utama dari ruang publik tersebut. Adapun faktorfaktor mempengaruhi terjadinya pemanfaatan ruang publik di kawasan GOR H. Agus Salim Kota Padang sebagai berikut: 


\section{Lokasi yang Strategis}

Kawasan GOR H. Agus Salim yang terletak pada pusat kota yang beralokasi Kelurahan Rimbo Kaluang Kecamatan Padang Barat cukup terbilang strategis, memudahkan masyarakat untuk menjangkau tempat ini. Kawasan yang juga dekat dengan Mesjid Raya kota Padang dan juga dekat dengan kawasan pantai Padang yang menjadi salah satu tujuan wisatawan. Yang terpenting adalah kawasan ini dilengkapi dengan sarana dan prasarana olahraga, untuk dapat dimanfaatkan oleh semua kalangan masyarakat. Masyarakat dapat berolahraga dengan bebas dan menggunakan fasilitas-fasilitas yang ada.

Namun lokasi kawasan GOR H. Agus Salim yang strategis dan berada di pusat kota membuat beberapa pihak berfikir untuk menggunakannya, selain menjadi tempat aktivitas olahraga juga digunakan untuk aktivitas lainya seperti adanya aktivitas ekonomi, aktivitas sosial dan lain sebagainya, tetapi yang paling mendominan dari semua aktivitas tersebut adalah aktivitas ekonomi karena berbagai kegiatan besar diselenggarakan di kawasan ini seperti padang fair, pergelaran kesenian, berbagai festival yang dilatar belakangi oleh faktor ekonomi. Kawasan yang terletak dipusat kota membuat masyarakat tertarik untuk menggunakan kawasan GOR H. Agus Salim sebagai lahan yang menguntungkan. Akan berbeda jika kawasan GOR H. Agus Salim terletak pada pinggir kota tentu kawasan ini akan sepi pengunjung.

\section{Akses yang Mudah}

Kawasan GOR yang strategis tentunya didukung dengan akses yang mudah untuk menjangkau tempat ini. Kawasan ini dapat dijangkau dengan kendaraan pribadi maupun dengan kendaraan umum. Kawasan ini selalu dipadati dengan kendaran-kendaran masyarakat. Kawasan GOR H. Agus Salim dapat dimasuki dari berbagai arah seperti dari jalan Raden Saleh, jalan Rasuna Said, jalan Ir H. Juanda. Selain itu, kawasan ini berada dekat dengan jalan raya. Jadi akses jalan yang mudah juga memudahkan masyarakat untuk mendatangi atau mengunkunjungi tempat ini.

Selain akses jalan juga terdapat akses yang mudah untuk mendapatkan surat izin menggunakan kawasan GOR H. Agus Salim untuk kepentingan-kepentingan tertentu. Seperti surat izin untuk berdagang, penyelenggarakan berbagai kegiatan yang bersifat non keolahragaan, masyarakat hanya perlu mendapatkan berupa surat izin dari pemerintah untuk menggunakan kawasan ini, dengan membayarkan sejumlah distribusi kepada pemerintah. Distirbusi dari masyarakat akan mengalir pada pendapatan asli daerah (PAD) kota Padang. Namun tidak semua aktivitas yang terdapat di kawasan GOR H. Agus Salim membutuhkan izin.

\section{Kawasan yang Memiliki Daya Tarik}

Daya tarik merupakan potensi/kekuatan yang membuat orang lain mempunyai perhatian khusus terhadap sesuatu. Salah satu faktor pendukung terjadinya pemanfaatana ruang publik di kawasan GOR. H. Agus Salim adalah kawasan yang memilik daya tarik, daya tarik merupakan salah satu faktor pendorong. Adapun daya tarik yang dimiliki kawasan ini dapat berupakan kondisi lingkungan, sarana dan prasarana yang dimiliki, yang terpenting adalah kawasan ini merupakan kawasan penghijauan di Kota Padang. Selain itu kawasan ini merupakan kawasan penyedia fasilitas keolahragaan, kawasan ini cocok digunakan untuk menampung aktivitas masyarakat.

Daya tarik yang dimiliki kawasan GOR H. Agus salim ini menjadi salah satu faktor terjadinya pemanfaatan ruang publik yang tidak sesuai dengan fungsinya. Daya tarik tersebutlah yang membuat oknumoknum untuk menggunakan kesempatan ini dengan mengambil keuntungan. Selain itu kawasan GOR H. Agus Salim menjadi salah satu tujuan tempat reflesing bagi masyarakatnya. Hal ini juga menjadikan daya tarik masyarakat untuk menggunakan fasilitas-fasilitas publik untuk menjadi tempat yang dapat digunakan oleh siapa saja.

\section{Lemahnya Kontrol Sosial}

Kontrol sosial atau kata lainya adalah pengendalian sosial merupakan suatu proses yang direncanakan atau tidak yang sifatnya mendidik, mengajak bahkan memaksa warga masyarakat agar mematuhi nilai-nilai sosial yang berlaku. Kawasan GOR H. Agus Salim dimana telah terjadi perubahan fungsi atau kawasan yang multifungsi, hingga perlunya kontrol sosial atas aktivitas-aktivitas yang dilakukan. Penting adanya kontrol sosial di kawasan GOR H. Agus Salim agar dapat mengawasi dan penertibkan kegiatan-kegiatan yang merugikan diri sendiri maupun masyarakat. Kontrol sosial dapat dilakukan oleh masyarakat maupun pemerintah. Lemahnya kontrol sosial yang ada di kawasan GOR H. Agus Salim hingga terjadi berbagai aktivitas baik itu aktivitas yang melanggar nilai dan norma maupun aktivitas yang melanggar peraturan pemerintah. Terjadinya saling ketergantungan antara masyarakat dan pemerintah sendiri, hingga pemerintah juga tidak bisa bersikap tegas kepada pengguna kawasan. Melemahnya kontrol sosial terjadinya tidaknya adanya sikap yang saling menyikapi permasalahn yang ada secara tegas. Maka dari itu penyalahgunaan kawasan ini terus berlanjut dan terus ada. 
Kawasan GOR H. Agus Salim sebagai sarana dan prasarana olahraga di Kota Padang merupakan barang milik daerah yang pengelolaannya diatur dalam Peraturan Pemerintah. Pengelolaan tersebut harus sesuai dengan fungsi dan asas-asas pengelolaan barang milik daerah tercantum dalam Pasal 3 ayat (1) PP Nomor 27 Tahun 2014. Kawasan GOR H. Agus Salim yang telah beralih fungsi salah satunya disebabkan oleh lemahnya kontrol sosial, terutama dari pemerintah untuk metindaklanjuti pihak pihak yang telah memanfatkan kawasan GOR menjadi lahan untuk kepentingan pribadi. Sehingga mereka secara leluasa menggunakan tempat ini, meskipun ada beberapa bentuk teguran tertulis maupun lisan dari pihak terkait pengelolah kawasan GOR ini tetapi masih saja mereka menggunakan kawasan ini, disebabkan oleh teguran yang mereka dapatkan tidak memberikan efek jerah. Maka dari itu, perlunya peraturan mengenai ruang publik di Kota Padang.

\section{PEMBAHASAN}

Teori struktural fungsional yang dikemukakan oleh Robert K Merton yang dikenal dengan konsep fungsi manifes (yang diharapkan) dan fungsi laten (tidak diharapkan). Kawasan GOR H. Agus Salim merupakan kawasan yang diperuntukkan untuk kegiatan olahraga, maka dari itu kawasan ini dapat dimanfaatkan untuk menyelenggarakan berbagai cabang keolahrgaan. Kawasan GOR H. Agus Salim menyediakan sarana dan prasarana keolahragaan, yang dapat dipergunakan untuk semua kalangan masyarakat baik dari Kota Padang maupun luar Kota Padang. Sehingga diharapkan masyarakat memiliki taraf hidup yang sehat secara jasmaniah dan rohaniah. Selain itu masyarakat dapat memanfaatkan kawasan ini sesuai dengan peruntukkanya sebagai kawasan olahraga.

Namun kawasan GOR H. Agus Salim telah beralih fungsi menjadi kawasan yang multifungsi. Artinya semua kegiatan yang bersifat non keolahragaan dapat diselenggarakan di kawasan ini. Banyaknya masyarakat memanfaatkan kawasan ini untuk kepentingan-kepentingan tertentu. Sehingga kawasan GOR H. Agus Salim menjadi wadah/tempat penyalur berbagai aktivitas-aktivitas masyarakat dengan beragam kegiatan dan perilaku masyarakatnya.

\section{KESIMPULAN}

Kesimpulan yang didapat dari pemanfaatan ruang publik di kawasan GOR H. Agus Salim Kota Padang adalah Pertama, lokasi yang strategis artinya lokasi yang terletak dipusat kota dan keramaian. Kedua, akses yang mudah dilihat dari perolehan izin, transportasi dan lain sebagainya. Ketiga, kawasan yang memilik daya tarik didukung oleh kondisi lingkungan, sarana dan prasarana. Keempat, lemahnya kontrol sosial baik itu dari pemerintah maupun dari masyarakat dalam menindaklanjuti para pengguna ruang/tempat. Adapun saran yang dapat diberikan yaitu pemerintah dan masyarakat dapat bersikap dengan bijak dalam menggunakan ruang/tempat yang sesuai dengan peruntukkannya.

\section{DAFTAR RUJUKAN}

Afrizal. (2008). Pengantar Metode Penelitian Kualitatif: Dari Pengertian Sampai Penulisan Laporan. Unand: Laboratorium Sosiologi FISIP Unand.

Anita Juarni, dkk. (2012). Kajian Terhadap Ruang Publik Sebagai Sarana Interaksi Warga di Kampung Muararajeun Lama, Bandung. Jurnal Online Institut Teknologi Nasional, 1 (1)

Bungin, Burhan. (2012). Metode Penelitian Kualitatif; Aktualisasi Metodologis Ke Arah Ragam Varian Kontemporer. Jakarta. Rajawali Pers.

Budihardjo, Eko, dkk. (1999). Kota Berkelanjutan. Bandung: Yayasan Adikarya Ikapi \& The Ford Foundation.

Handayani, Suci. (2009). memahami Pelaku Sektor Informal Perkotaan: Penataan Pedagan Kaki Lima Tanpa Kekerasan. Jurnal Analisis Sosial, 14 (1)

Iskandar. (2009). Metodologi Penelitian Kualitatif (Aplikasi Penelitian Pendidikan, Hukum, Ekonomi \& Manajemen Sosial, Humaniora, Politik Agama Dan Filsafat) jakarta: GP Press.

Milles, M.B. and Huberman, M.A. (1984). Qualitative Data Analysis. London: Sage Publication.

Moleong, Lexy J. (2006). Metodologi Penelitian Kualitatif. Bandung: PT Remaja Rosdakarya.

Poloma, Margaret M. 1994. Teori Sosiologi Kotemporer. (alih bahasa: Tim penerjemah Yosogama). Jakarta: raja Grafindo Persada.

Sugiyono. (2010). Metode Penelitian Kuantitatif Kuantitatif Dan R\&D. Bandung: Alfabeta.

Wirawan. (2012). Teoroi-Teori Sosial Dalam Tiga Pradigma (Fakta sosial, Defenisi Sosial dan Perilaku Sosial). Jakarta: Kencana Prenada Media Group.

Peraturan Daerah Kota Padang No 3 Tahun 2014 Tentang Penataan dan Pemberdayaan Pedagang Kaki Lima. (www.jdih.setjen.kemendagri.go.id) 